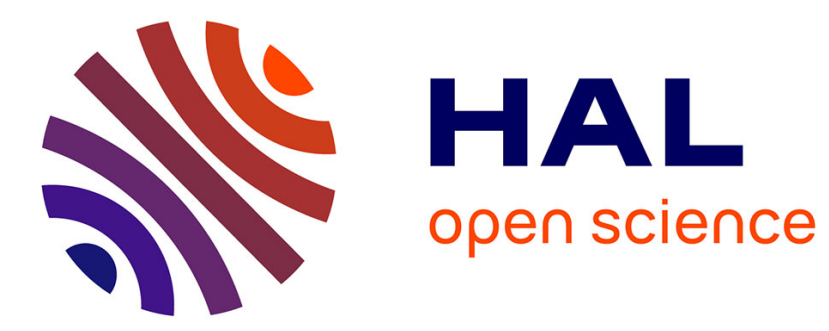

\title{
METROLOGY AND DYNAMIC BEHAVIOUR OF SOLIDS
}

M. de Gliniasty

\section{To cite this version:}

M. de Gliniasty. METROLOGY AND DYNAMIC BEHAVIOUR OF SOLIDS. Journal de Physique Colloques, 1984, 45 (C8), pp.C8-245-C8-256. 10.1051/jphyscol:1984847 . jpa-00224348

\section{HAL Id: jpa-00224348 https://hal.science/jpa-00224348}

Submitted on 1 Jan 1984

HAL is a multi-disciplinary open access archive for the deposit and dissemination of scientific research documents, whether they are published or not. The documents may come from teaching and research institutions in France or abroad, or from public or private research centers.
L'archive ouverte pluridisciplinaire HAL, est destinée au dépôt et à la diffusion de documents scientifiques de niveau recherche, publiés ou non, émanant des établissements d'enseignement et de recherche français ou étrangers, des laboratoires publics ou privés. 
Commissariat à l'Energie Atomique, Centre d'Etudes de Vaujours, B.P. $n^{\circ} 7$, 77181 Courtry, Erance

Résumé - La plupart des difficultés rencontrées dans l'étude du comportement dynamique des matériaux sont d'ordre expérimental. Il y a une quarantaine d'années, lorsque débutèrent les études sur les ondes de choc dans les solides, l'expérimentateur ne disposait que de contacts électriques; seule la mesure de déplacement était possible. L'apparition dans les années 60 de capteurs capables de mesurer des profils de pression ou de vitesse a permis des progrès considérables dans la compréhension du comportement dynamique des matériaux. Mais aujourd'hui, il devient nécessaire d'explorer l'épaisseur même du front de choc. Heureusememnt le développement de nouvelles techniques optiques (telle la spectro RAMAN) offre de belles perspectives dans cette voie.

Abstract - Dealing with dynamic behaviour of solids mainly involves metrology problems. When the shock wave studies began, forty years ago, only pins were available. Discrete displacement versus time could be measured. Major improvements came in the sixties with pressure and velocity profile measurements. Since that time, a large amount of data has been gathered and, within the frame of continuum theory, constitutive relations taking into account elastic failure, phase transitions, rate effects, have been proposed. But it has become necessary to get down to the thickness of the shock front. Fortunately, the development of new optical techniques, such as RAMAN spectroscopy, offers potentials for that.

\section{INTRODUCTION}

To give a review of the dynamic behaviour of materials and of the metrology of high dynamic pressures in forty minutes is a challenge : although shock physics in solids is a rather recent branch, only forty years old, a considerable amount of work has been done and many comprehensive reviews have been published already (see for example [1] , [2] ).

Before getting down to the main part of the talk, I would like to emphasize the tight link between measurement techniques and the modeling of the dynamic behaviour of materials. Remember that we are dealing with waves propagating at velocities of several $\mathrm{km} / \mathrm{s}$ and with states persisting for only a few microseconds or even nanoseconds. It is clear then, that our knowledge of what happens is strongly influenced by experiment : we are in fact totally dependant on the images obtained from the various sensors that have been developped. As a direct consequence of this statement, the theory usually follows the experiment.

Because of time limitations and because of my own background, I shall restrict the talk to plane waves of uniaxial strain in materials in which shear stress exists, i.e. mainly solids.

\section{GENERATION OF HIGH DYNAMIC PRESSURES}

To begin this talk, I would like to say a few words on how to produce high dynamic pressures. The easiest way is to generate shock waves and there are different methods of doing so :

- to detonate an explosive in contact with the sample,

- to impact a projectile accelerated by explosive or by a gun,

- to deposit energy inside the sample by means of an electron beam or a laser beam, 
- to use nuclear explosion for very high pressures.

To achieve good quality plane waves, the use of guns is more appropriate ; moreover their different types (gas gun, powder gun, two stage light gas gun, electric gun) enable the shock physicist to reach a large pressure scale.

The major disadvantages of using explosive is that the pressure pulse is not sustained, and of course special facilities are necessary. As for energy deposition, one needs large machines to achieve high pressures. In this last case, the pressure is raised at constant volume, so the initial state is different.

Figure 1 shows in a Pressure-Specific volume plane, the range of pressures achievable in copper by those different means. The locus of the final states produced by a simple shock wave is a curve : the Rankine-Hugoniot curve ( $R$ H).

As it has been often pointed out, it is easier to generate high dynamic pressures with shock waves, than static ones. But the problem is more complicated when one tries to reach high dynamic pressures off the R-H curve. Let me say a few words about the corresponding methods.

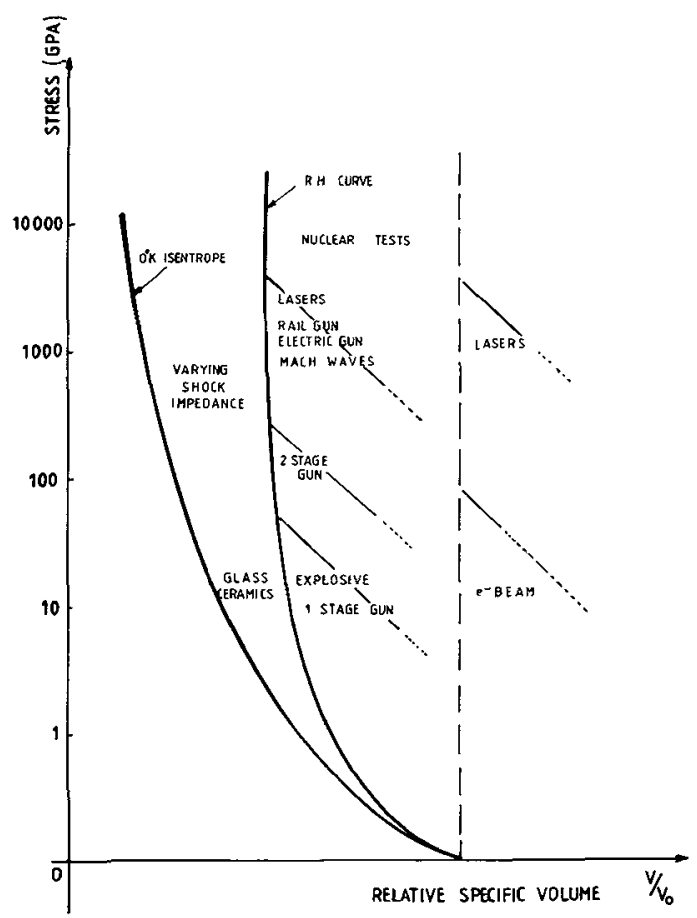

Fig. 1 : Range of pressures achievable in copper

Investigation of the zone at the right of the R-H curve, can be done with porous materials. It was proposed as early as 1953 by WALSH and CHRISTIAN [3], but the interpretation of the results is rather complicated. We shall come back to that when dealing with the problem of internal state variables.

Far more difficult is the access to the zone between the isentropic cold compression curve and the R-H curve. Many attempts have been made since 1972 (a complete bibliography is given in [4] ). Good results were obtained up to nearly $30 \mathrm{GPa}$, using glass ceramics which present a non linear elastic behaviour, by BENEDICK and ASAY [5] in 1976. In order to obtain higher pressures, another method must be used : the projectile with varying shock impedance. The first successful published results are due to BARKER [6] with his "pillows". Various ramp waves up to $200 \mathrm{GPa}$ have been successfully produced. I shall come back to that point later on.

\section{THE DISPLACEMENT VS TIME MEASUREMENTS PERIOD}

This type of diagnostic was the first to be used because of its simplicity. Before presenting some examples, let me show you how those measurements could be used to obtain equation of state data.

In the most general case of the continuum theory, the conservation laws may be written as follows in any specified volume $V$, of surface $S$ and normal $n$ :

- mass conservation : $\frac{d}{d t} \int(v) \rho d v=0$

- momentum conservation: $\frac{d}{d t} \int(v){ }^{u_{i}} d v=\int(s){ }^{t_{i j}}{ }^{n_{j} d s}+\int(v){ }^{f_{i} d V}$ 
- energy conservation : $\frac{d}{d t} \int_{(v)} \rho\left(e+\frac{u^{2}}{2}\right) d v=\int_{(v)}\left(u_{i} f_{i}+q\right) d v+\int_{(s)}\left(u_{j} t_{i j}-Q_{i}\right) n_{i} d s$

where $\rho$ is the density, $u$ the particle velocity, $t_{i j}$ the stress tensor, $f_{i}$ the volumic forces, $e$ the internal energy, $q$ the volumic energy provided by the surroundings and $Q_{\text {i }}$ the surfacic heat flux. If there is a discontinuity surface inside the volume, each integral form can be shared in two parts : a volumic integral form and a jump accross the discontinuity. In the simplest case of a hydrodynamic medium with no internal sources and an adiabatic transformation in one dimensional plane geometry, the jump equations are reduced to the well known Hugoniot equations :

$\mathrm{V} / \mathrm{v}_{\mathrm{o}}=\left(\mathrm{U}_{\mathrm{s}}-\mathrm{u}_{\mathrm{p}}\right) / \mathrm{U}_{\mathrm{s}}, \quad \mathrm{P}-\mathrm{P}_{\mathrm{o}}=\mathrm{U}_{\mathrm{s}} \mathrm{u}_{\mathrm{p}} / \mathrm{V}_{\mathrm{o}}, \mathrm{E}-\mathrm{E}_{\mathrm{o}}=1 / 2\left(\mathrm{P}+\mathrm{P}_{\mathrm{o}}\right)\left(\mathrm{V}_{\mathrm{o}}-\mathrm{V}\right)$ with $V$ specific volume, $U_{s}$ shock velocity, $u_{p}$ particle velocity, $P$ pressure and $E$ specific
internal energy.

When the shock waves studies began, forty years ago, only pins were available. The measurement of the free surface velocity $u_{f s}$, with the assumption that it is twice the particle velocity, and of the shock velocity $\mathrm{U}_{\mathrm{s}}$, allows the other quantities to be estimated. But this is valid only with a very simple picture of a shock wave, such as the one showed in figure 2.

Experimental R-H curves were obtained in 1944 (see [3] ) and equations of state, of the Mie-Gruneisen type, were proposed :

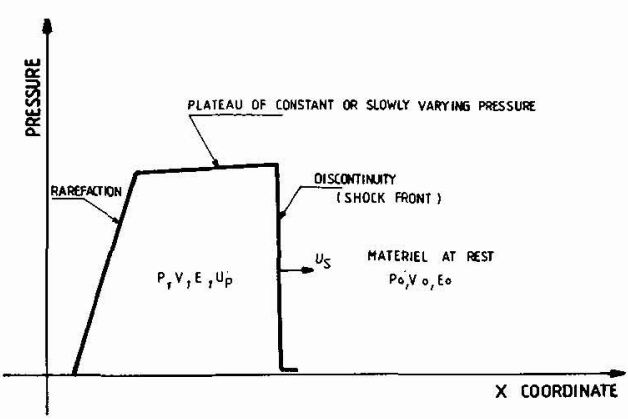

Fig. 2 : Simple shock wave picture $P-P_{\text {ref }}=\frac{\gamma(V)}{V}\left(E-E_{\text {ref }}\right)$, where $\left(P_{\text {ref }}, E_{\text {ref }}\right)$ is a reference curve in the $P, V, E$ space.

Note that this is not a complete equation of state, in the sense that the thermal parameters ( $T$

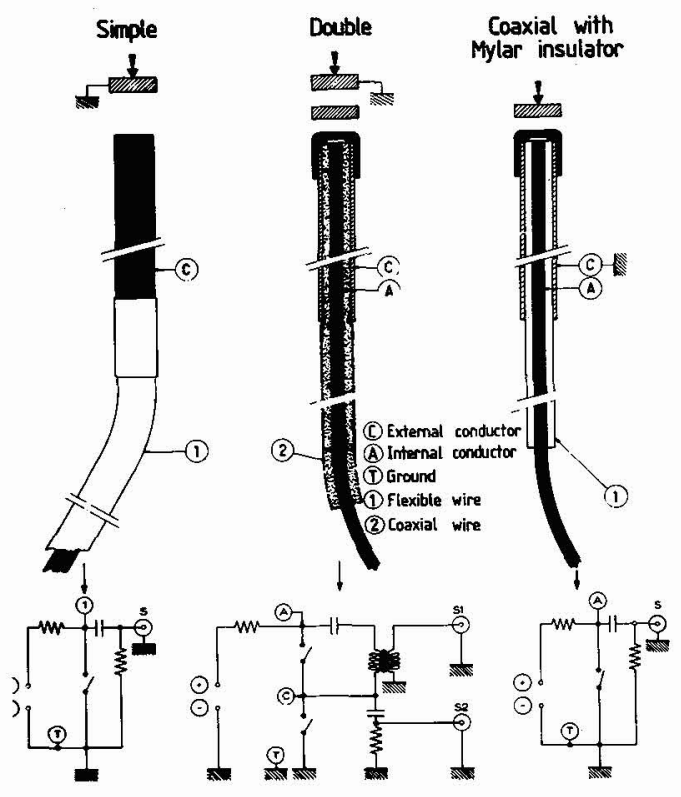

Fig. 3 : Scheme of electrical pins and S) cannot be explicitly calculated. Figure 3 is a scheme of typical pins with their power supply. These pins are of different types : one conductor, coaxial or coaxial with a film of insulator (usually mylar) at the top ; the last model is particularly suited to shock velocity measurements.

It is interesting to notice that pins are still largely used to day (see [7] and [8] for example) although far more precise techniques, such as the Döppler Laser Interferometry (DLI), have been developped. This is because at high velocities (or pressures) the precision of electrical pins is as good as DLI's.

As an example figure 4 describes a recent pin developped by C.E.A. [9] . This is a self generating pin, i.e. which does not need any power supply. The signal is the flash of light produced by the ionization under compression of the air gap at the top of the pin. 
The light is recorded through an optical fiber on an optoelectronic streak camera THOMSON TSN 503.

A similar optical probe has been developped at LLNL [10], but the air is replaced by Xenon in order to record the signal on a rotating mirror camera.

The next step in the development of measurement techniques was the continous displacement versus time detectors. In that category we find the $\mathrm{DC}$ capacitor gauge (mentionned in 1945 [3]), but mainly the rotating mirror cameras (BRIXNEL 1952).

A scheme of a streak rotating mirror camera is given in figure 5. Streak and framing cameras are still largely used to day : even if the interpretation is sometimes difficult, nothing can replace a good image of a phenomenon. I must mention also the displacement interferometer, but it has not been used very often since the velocity interferometer appeared.
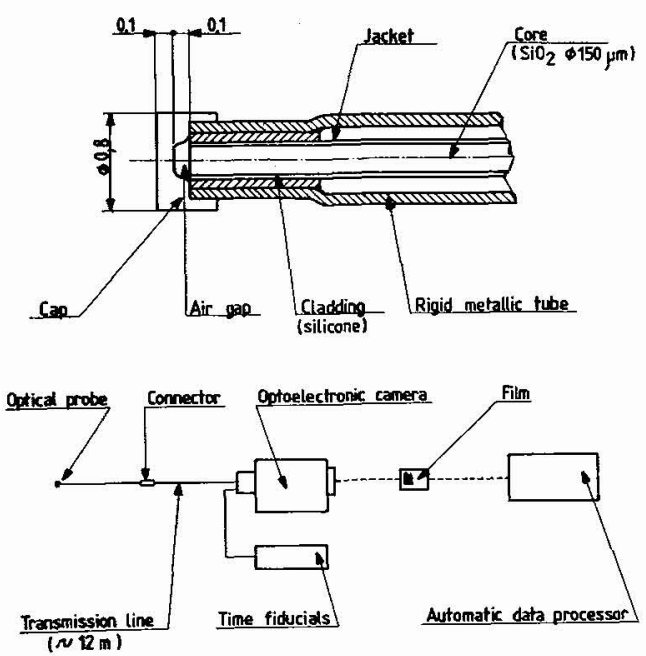

Fig. 4 : CEA Optical pin

As I told you at the beginning, the theory usually follows the experiment, and as an illustration of that statement, let me mention that all the typical features of a shock wave in a solid have been discovered with those simple displacement vs time detectors :

- the elastic behaviour of metals (PEIRLS and STEIN 1945 [3])

- spalling, at the same time [3]

- phase transitions under shock loading (WALSH and CHRISTIAN 1954 [3] )

The evidence of a two waves structure, in that last case, was given in 1954 but the theoretical explanation was found in 1956.

In 1959 another step was taken : DC capacitor records showed that the concept of sharp elastic and plastic waves had to be discarded. Finite rise-times were evidenced and the question of rate effects was raised. The shock picture in iron for example could be modelized as it is shown in figure 6.

But to proceed, i.e. to establish proper models, a new instrumentation was necessary.

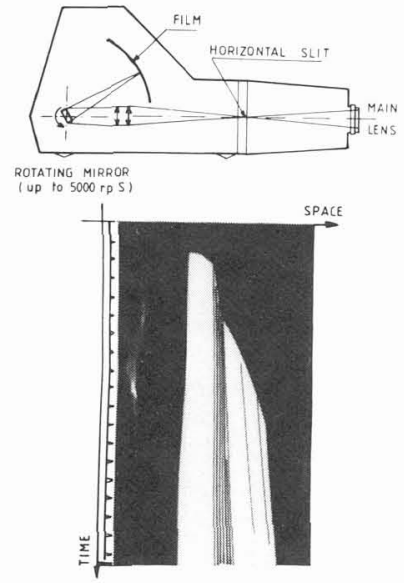

Fig. 5 : Streak camera

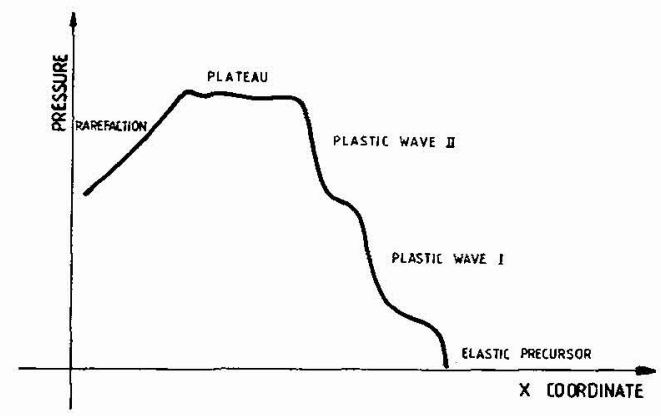

Fig. 6 : Shock picture 


\section{CONTINUOUS VELOCITY OR STRESS VS TIME MEASUREMENTS}

Fortunately new powerful diagnostics appeared early in the sixties :

- the electromagnetic velocity gauge EMV (ZAITSEV 1960 [11], DREMIN 1964 [12]),

- the quartz piezoelectric gauge, (JONES 1962 [13])

- the manganin piezoresistive gauge (FULLER and PRICE 1962, [14]),

- the velocity interferometer (LAHARRAGUE-DURAND 1969 [15], [16]

- the VISAR (BARKER-HOLLENBACH 1972, [17] ),

- and many others (see [2] ).

All those techniques are widely used to day, instead of the displacement devices. It is clear why this is so : the displacement vs time data must be differentiated before the wave profiles of interest are obtained. I shall describe the most commonly used techniques.

The principle of the EMV gauge is very simple (figure 7 ) : a loop of a conductive material (usually anodized aluminum)is embedded inside the sample, in a constant magnetic field $\mathrm{B}$. The magnetic field can be produced either by coils or by permanent magnets.If 1 is the length of the conductor, $u$ its velocity, an electromotive force $e$ appears at the terminals of the loop (Faraday's law):

$\mathrm{e}=\mathrm{B} 1 \mathrm{u}$

So the recorded voltage is directly proportional to the velocity of the conducting loop, that is to say to the particle velocity of the medium.

Note that the medium must be non conductive.

The most widely used piezoelectric quartz gauge, has been designed by GRAHAM [18]: it is the ring $X$-cut quartz gauge (fig. 8 ).

It consists in a mono crystalline piece of $X$ oriented quartz which is metal deposited except on a ring at its back face.

The piezoelectrically produced polarization in a state of one dimensional strain is proportional to the applied stress, if the quartz remains linearly elastic (and dissipationless).
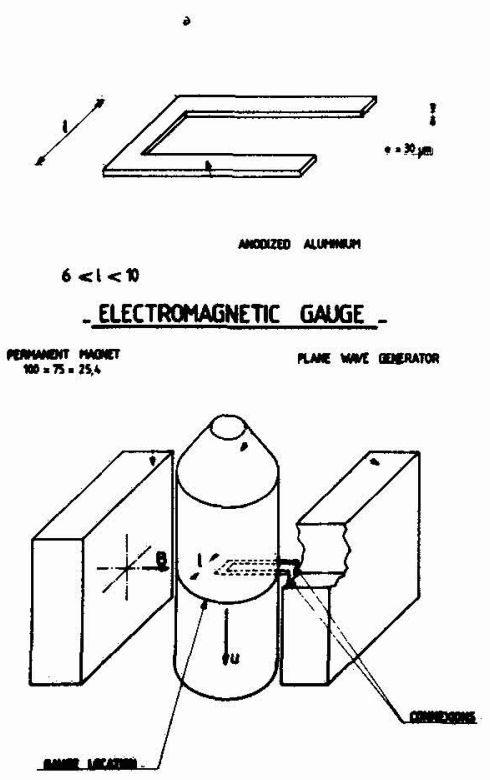

- EXPERMFENTAL SET UR.

Fig. 7 : Principle of EMV gauge

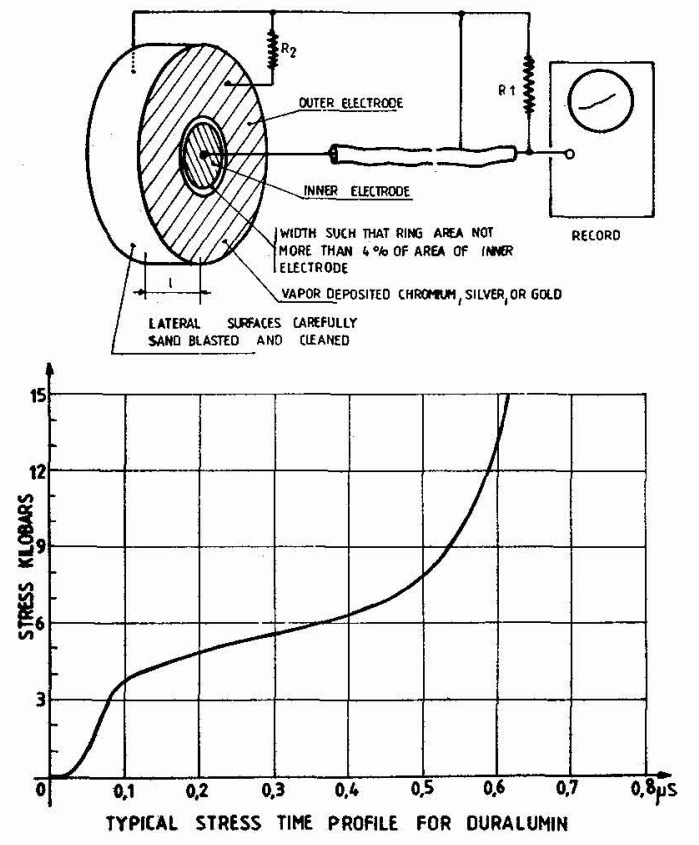

Fig. 8 : X-cut quartz gauge (from [18] ) 
Then the current-time waveform is directly proportional to the interface stress-time profile : $\sigma_{q}(0, t)=1 i(t) / A k V_{q}$ for $t 1 / V_{q}$, where $A$ is the area, 1 the thickness of the quartz and $V_{q}$ its dilatational elastic wave velocity.

Although it gives a precise measurement with a good time resolution ( 1 to $5 \mathrm{~ns}$ ), the quartz gauge presents some disadvantages : pressure limited to nearly $2 \mathrm{GPa}$ (Hugoniot elastic limit of quartz), and pressure measured inside the quartz instead of the sample. A review on piezoelectricity is given in [19].

The manganin piezoresistive gauge is more versatile. A typical low impedance gauge [20] is presented in figure 9.

Embedded inside the material, it gives the pressure inside the sample, up to 50 to $60 \mathrm{GPa}$.

The low impedance gauge needs a constant current power supply and the voltage is collected at the terminals of the active part (manganin).

The typical resistance of such gauges is less than $0,1 \Omega$. High impedance gauges $(25$ or $50 \Omega$ ) are also available, but they need a constant voltage power supply through a Wheatstone bridge. They are limited to 15 - $20 \mathrm{GPa}$, maximum pressure.

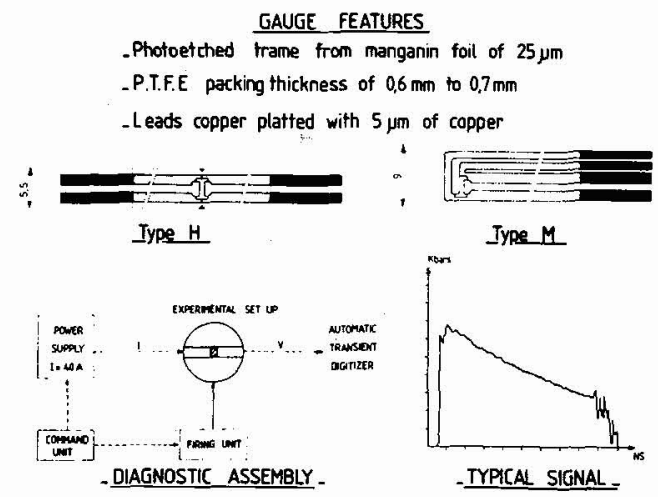

Fig. 9 : Low impedance Manganin gauge

The main disadvantage of the manganin gauge is its time resolution due to the thickness of the insulation : more than $50 \mathrm{~ns}$.

The manganin gauge, used as a lagrangian gauge, withstands the rarefaction waves, so it gives useful information on the release behaviour of materials. This is not the case for Carbon piezoresistive gauges [21]. But these Carbon gauges are more precise at low pressures $(<5$ $\mathrm{GPa}$ [22] . Ytterbium piezoresistive gauges have also been used [23] to a small extent. All the piezoresistive gauges have to be calibrated.

But the major improvement in the techniques of high dynamic pressure measurement has been the velocity interferometer, by means of Döppler laser interferometry (DLI).

Two types of velocimeter are in use to day: the DLI device with a Fabry-Perot interferometer and the VISAR with a Michelson interferometer. A schematic view of a Fabry-Perot velocity interferometer is shown in figure 10.

The velocity $\mathrm{V}$ of the target is proportional to the space between the fringes (cf. fig. 10)

A pretty good surface finish of the target is necessary to get clear recordings on the streak camera.

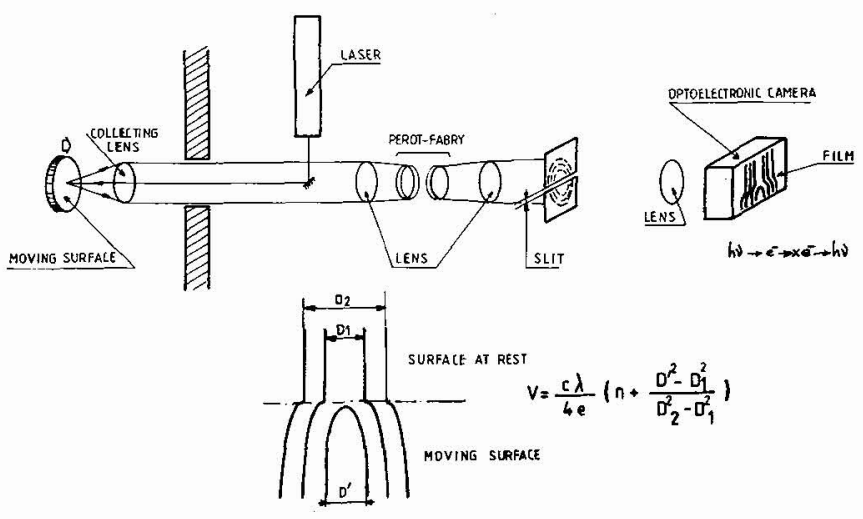

Fig. 10: Döppler Laser Interferometer 
The velocity resolution depends on the space between the mirrors of the Fabry-Perot. A few meters per second is a typical value. Time resolution may be estimated at 1 to 5 ns. Now DLI devices with beam transportation through optical fibers are currently developped [24] .

The VISAR is slightly more complicated as it appears in figure 11. The delay leg of the Michelson may be a glass cylinder or simply air. The results are recorded on photo-multiplier tubes.

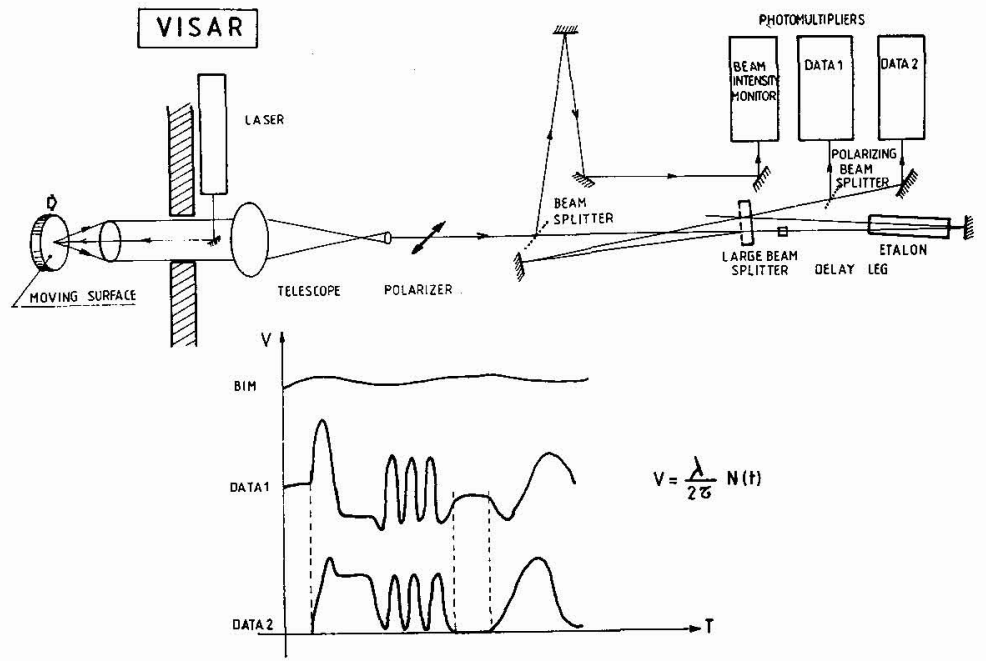

Figure 11: VISAR

Two fringe signals, which are $90^{\circ}$ out of phase, are simultaneously recorded to improve accuracy and to distinguish acceleration from deceleration. The time resolution of the VISAR is also 1 to $5 \mathrm{~ns}$.

Figure 12 is an illustration of a DLI record. The experimental set up is shown in the figure and two different measurements are recorded : the copper buffer plate velocity and the sample (steel) velocity [25].

On such a record, the following events are detected :

- $A=$ elastic precursor

- $B=$ reflection on the plastic I wave $\quad C$ of the reflected elastic wave on the free surface

- $C=$ plastic I wave

- $D=$ reflection on the plastic II wave $E$ of the reflected plastic wave $I$ on the free surface

- $\mathrm{E}=$ plastic II wave

- F = PIR wave [26]
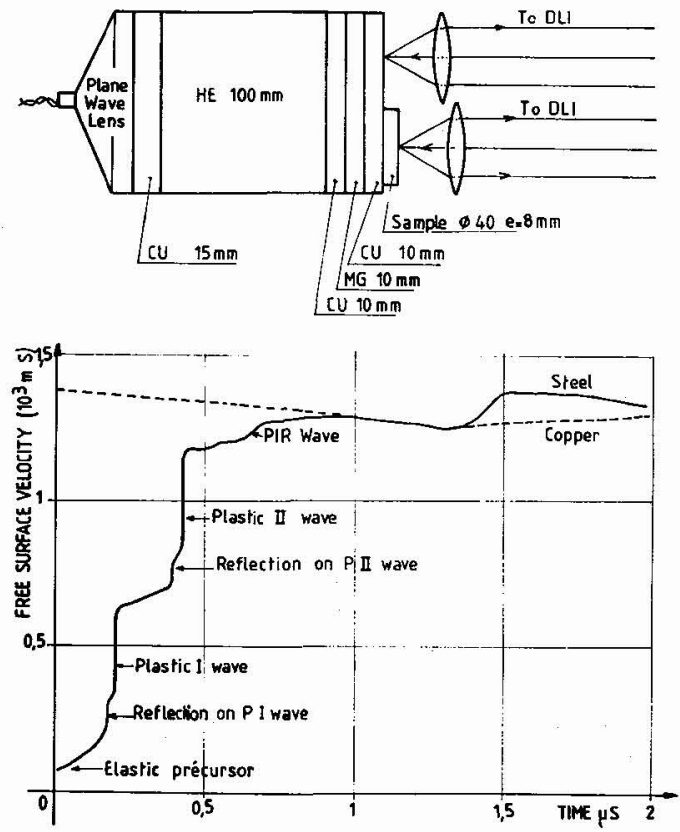

Figure 12 : Typical DLI experiment 
With some simple assumptions, such as centered compression wave [26], the following quantities may be derived: elastic wave velocity $C$, Hugoniot elastic limit HEL, Poisson ratio $\nu$, plastic yield $\gamma$, pressure of the phase transition $\alpha \rightarrow \varepsilon$, and reverse $\varepsilon \rightarrow \alpha$. If spalling had occured, the spall-tension could have been measured.

All the techniques described above have been improved since their first appearance. To illustrate that point, let me present to you the electromagnetic stress and velocity gauge EMSVG [27], [28].
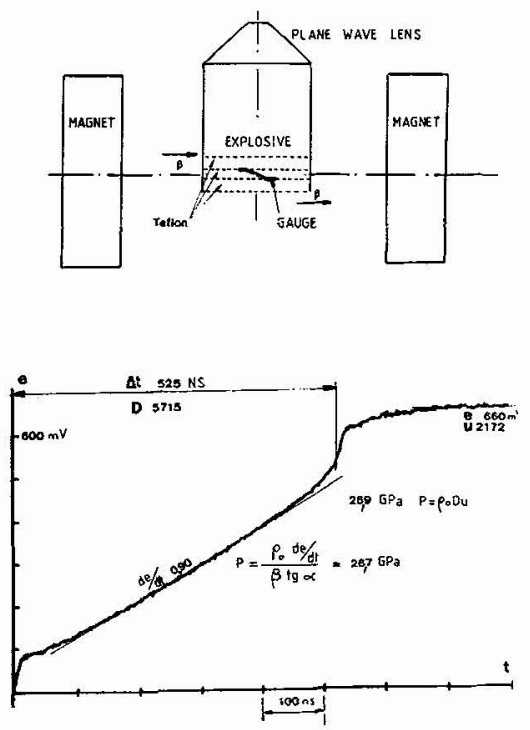

Fig. 13 : EMSV gauge

When you integrate, along lines of constant lagrangian coordinate $h$, over a short time interval $\left(t_{1}, t_{2}\right)$, the conservation laws (1) written in 1D plane geometry, you get :

$$
\begin{aligned}
& v_{2}=v_{1}+v_{0} \int_{t_{1}}^{t_{2}}\left(\frac{\partial u}{\partial h}\right)_{t} d t, u_{2}=u_{1}-v_{0} \int_{t_{1}}^{t_{2}}\left(\frac{\partial \sigma}{\partial h}\right)_{t} d t \\
& E_{2}=E_{1}-v_{0} \int_{t_{1}}^{t_{2}}\left(\frac{\partial u}{\partial h}\right) d t
\end{aligned}
$$

It is clear that the knowledge of $6(\mathrm{~h}, \mathrm{t})$ and its derivatives is sufficient to calculate all the other parameters $(u, E, V)$, without any information or assumption about the equation of state. The same is true with $u(h, t)$ and its derivatives, but it is slightly more difficult. To day, nearly all the lagrangian experimental data (manganin or carbon gauges, EMV gauge, DLI) are so processed.

Figure 14 shows a typical experiment with the pressure records by means of manganin gauges and the resulting thermodynamic pathes at different lagrangian coordinate location, in a P-V plane. The detailed procedure of the lagrangian analysis may be found in [31].

Figure 13 is a schematic drawing of a similar gauge, designed by CEA.

It consists of a loop, of a special shape, made of anodized aluminium embedded inside the material. A magnetic field is produced, as in the case of the EMV gauge. It allows recording of :

- the shock velocity $\mathrm{U}_{\mathrm{s}}$,

- the particle velocity $\mathrm{s}$,
- the pressure P.

A typical record is presented figure 13. Note that the EMSV gauge must be used in non conductive materials.

I have to mention a very powerful data analysis which was first proposed by FOWLES and WILLIAMS [29] improved by COWPERTHWAITE [30], and which is now widely used: the Lagrangian Analysis.

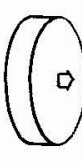

PROJEGTILE
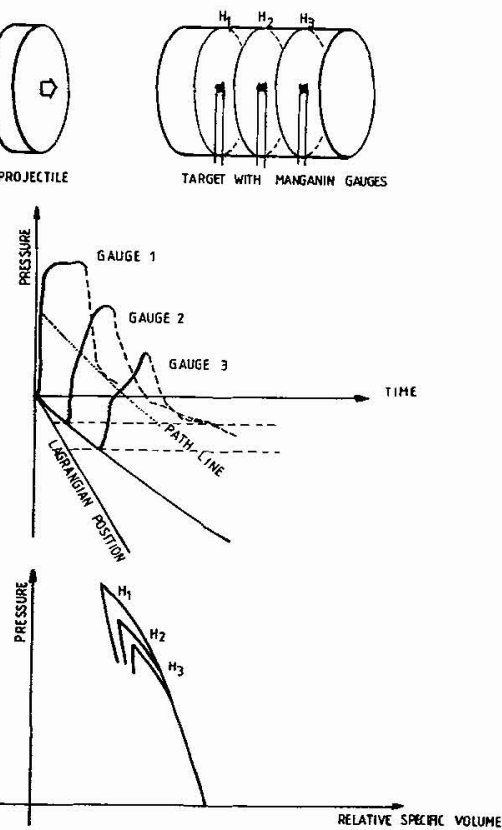

Fig. 14 : Lagrangian analysis 
The introduction of time resolved velocity and stress measurements has also considerably changed the classical constitutive relations representing the behaviour of specific materials.

For instance, complete experimental models for plastic yield surface have been built, using the experimental determination of deviatoric stress. There are several methods :

- the comparison of the Hugoniot curve with the hydrostat, which is no longer used,

- the unloading and reloading waves method [32] ,

- the combined compression and shear loading [33],

- the use of anisotropic crystals [34].

I shall describe here a method using manganin gauges [35]. The principle is to measure simultaneously the longitudinal stress $\sigma_{x}$ and the lateral stress $\sigma_{y}$. The sample is arranged as shown in figure 15. A full description of the method is given in [36]. In figure 15 the 6,6 , vs time results are shown in the case of PMMA.

Time resolved stress and velocity measurements have also allowed the development of rate effects models. Now they are taken into account, in the frame of the continuum theory, by means of internal state variables.
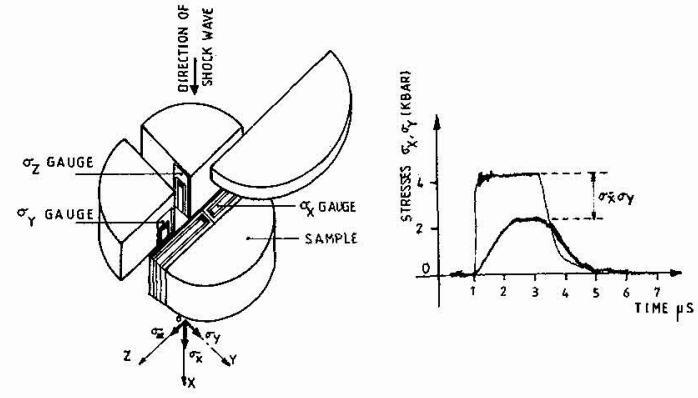

Fig. 15 : Deviatoric stress measurement (from [36])

Roughly speaking, a new parameter is introduced in the conservation laws or in the equation of state, and a new relation, usually time dependant and experimentally derived, is added. As examples; one can mention HERRMANN's $\alpha$ internal variable (which separates the volume variation due to the matrix compression from the void closure, in porous materials) [37] or the burnt mass fraction $\mathrm{g}$ in models for the initiation of explosives [38], or the density of dislocations in metals [39]. A complete review of the internal state variables problem is given in $[40]$.

\section{MISCELLANEOUS MEASUREMENTS}

A large effort has been devoted by shock physicists to temperature measurements. As early as 1946 [3] attempts were made using thermocouples, but unsuccessfully because of response time problems. Since then other methods have been tried (GIBSON [41], KATO [42], VON HOLLE [43], ROSENBERG [44]). But, as a transition towards future works on optical diagnostics, I shall only mention the method of BOISARD and DELPUECH [45], [46].

They use RAMAN spectroscopy. If $?$ is the RAYLEIGH frequency and $\nu_{0} \pm \nu_{i}$ the RAMAN frequencies the intensities of the Stokes and anti-Stokes lines may be expressed as :

$$
\begin{aligned}
& I_{S}=C_{i} I_{o}\left(\nu_{0}-\nu_{i}\right)^{4}\left(1-e^{-h \gamma_{i} / k T}\right)-1 \\
& I_{A S}=C_{i} I_{o}\left(\nu_{0}+\gamma_{i}\right)^{4}\left(e^{+h \gamma_{i} / k T}-1\right)^{-1}
\end{aligned}
$$

Where $I_{0}$ is the incident intensity, and $C_{i}$ a parameter including cross sections, medium density, optical apertures.

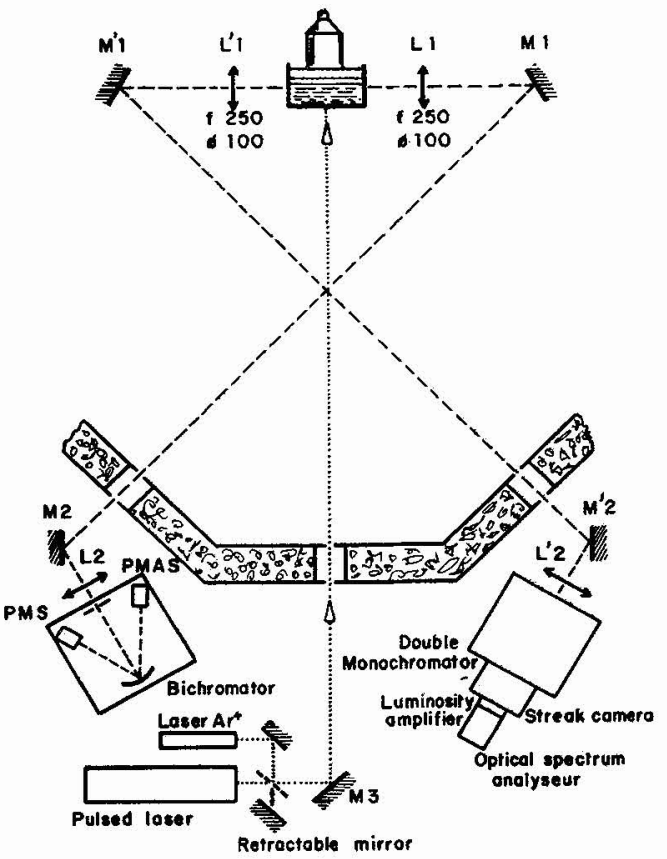

Fig. 16: Experimental set up for RAMAN spectroscopy 


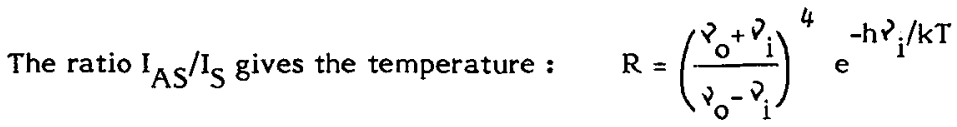

The experimental set up is pictured in figure 16. On the right side the RAMAN frequencies shifts due to shock compression of the medium are measured. On the left side the Stokes and anti-Stokes intensities are recorded with photomultiplier tubes.

Before concluding, I would like to say a few words about specific volume measurements : measuring $\mathrm{V}$ is difficult to carry out and, to my knowledge, the only technique is flash radiography. A special collimation method has been developped by GAUTHIER and GUIX [47] . The main disadvantage of this technique is that large radiographic machines are necessary.

\section{CONCLUSION}

To conclude with the measurement techniques appropriate to the continuum assumption, I must say that I have not compared the different sensors that can be used. This is on purpose : firstly because it would have been a very hard job, and secondly because the search for the best precision or time resolution is not necessarily the best aim. For example, although the velocity interferometer is to day the most precise technique, in some cases it may not be appropriate : as a matter of fact the measure is worked out on a very small area (typically $0,05 \mathrm{~mm}^{2}$ ) and grain size effects may alter the qualify of the measure. In that case, a manganin gauge, the active surface of which is a few $\mathrm{mm}^{2}$, may be more satisfactory.

After that review, one may think that everything has been done, from an experimental point of view, except measuring the entropy. But, of course that is not true. To illustrate that statement I shall briefly summarize results obtained by L. BARKER [6] on 6061T6 Aluminum with its "pillow" technique.

Comparing the stress-strain loading path determined from the quasi-isentropic wave profiles, to the Hugoniot points, he finds that at a given strain, the isentropic loading produces a higher stress, which is totally unexpected.

This strange result appears to be a manifestation of heterogeneous yielding and thermal trapping effects [4]: the very rapid localized deformation in Hugoniot experiments can cause localized heating on the shear planes with a resultant temporary loss of yield strength, which does not happen in the case of the slower deformation process of the quasi-isentropic experiment.

So the simple continuum assumption is no longer valid : it has

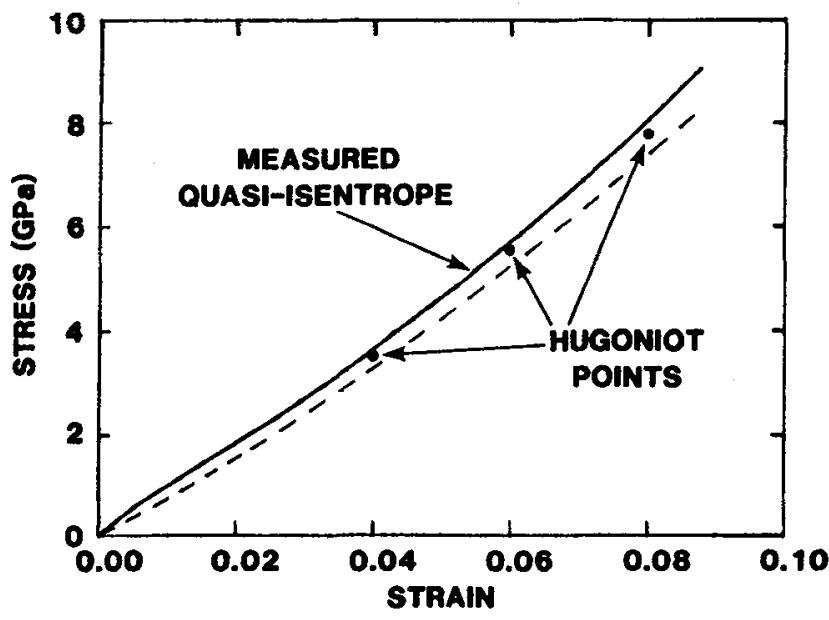

Fig. 17 : Quasi-isentropic compression results (from $|6|$ ) to be completed by internal state variables taking into account the microstructural deformations, the chemical transformation ... during dynamic loading.

More and more has been done in that field since a few years [48]. The usual technique is the recovery experiment, where a post-shock analysis of the sample is made after recovery (see for example [49], [50] ). But it is very difficult to define precisely the thermodynamic path followed by the sample during the whole experiment : it experiences release waves after compresssion. So it becomes necessary to carry on measurements within the shock front in a material.

To finish I shall say that we have already entered a new era in shock physics : the era of microstructural or even molecular comprehension of the dynamic behaviour of solids. Fortunately the development of optical sensors, such as RAMAN spectroscopy, offers potentials for achieving good measurements with the required spatial and temporal resolutions $(<1 /$ um, ( 100 ps). 


\section{REFERENCES}

[1] AL'TSHULER L.V., Sov. Phys. Uspekhi 8 (1965) 52

[2] GRAHAM R.A. in "High Pressure Science and Technology", 6 th ATRAPT Conf., K.D. TIMMERHAUS, M.S. BARKER Eds, Plenum Press (1979) 854

[3] Asummary of the "pioneering works" may be found in :

TAYLOR J.W., "Shock Waves in Condensed Matter" 1983 - J.R. ASAY, R.A. GRAHAM, J.K. STAUB EDS, Elsevier Science Pub. BV (1984) 3

[4] BARKER L.M., SCOTT D.D., Sandia Nationa1 Laboratories Rept SAND 84-0432 (1984)

[5] BENEDICK W.B., ASAY J.R., Bull. Am. Phys. Soc. 21 (1976) 1298

[6] BARKER L.M.," "Shock Waves in Condensed Matter" 1983 - E1sevier Sciences Pub. (1984) 217

[7] AL' TSHULER L.V. et a1., Sov. Phys. JETP 26 (1968) 1115

[8] GATHERS G.R. et al., "Shock Waves in Condensed Matter" 1983 - E1sevier Sciences Pub. (1984) 89

[9] GAUTHIER J.P., BOUCHU M., "proceeding of the 13 th International Congress on High Speed Photography and Photonics" TOKYO, SPIE Eds (1978) 667

[10] SHAW L.L. et a1., "Proceedings of the 12 th International Congress on High Speed Photography and Photonics TORONTO, SPIE Eds (1976)

[11] ZAITSEV V.M. et al., DokI. Acad. Sci. USSR 132 (1960) 1339

[12] DREMIN A.N., SHVEDOV K.K., J. Appl. Mech. and Tech. Fhys. 154 (1964)

[13] JONES O.E. et a1. J. A App1. Phys. 33 (1962) 3224

[14] FULLER P.J., PRICE J.H., Nature 193 (1962) 262

[15] LAHARRAGUE P. et al., CEA Rept DO 0015 (1969) unpublished

[16] DURAND M., LAHARRAGUE P., "Proceedings of the 9 th International Congress on high Speed Photography and Photonics" DENVER, SPIE Eds (1970)

[17] BARKER L.M., HOLLENBACH R.E., J. App1. Phys. 43 (1972) 4669

[18] GRAHAM R.A. et a1., J. App1. Phys. 36 (1965) 1775

[19] GRAHAM R.A., REEDS R.P., Sandia National Laboratories Rept SAND 78-1911 (1978)

[20] GUILLAMOT J.Y. et al. in "Premier Symposium sur les jauges et matériaux piezorésistifs" 29-30 Sept. 1981 ARCACHON - CEA, ADERA, CNRS PUb.
[21] CHAREST J.A.,EG.\& G. Rept DNA 3101F(1973)

[22] PEREZ M., CHARTAGNAC P.F., Rev. Scient. Instr. 41 (1980) 46

[23] GRADY D.E., GINSBERG M., J. App1. Phys . 48 (1977) 2179

[24] GIDON S. et a1. in "16 th Internationa1 Congress on High Speed Photography and Photonics "26-31 Aug. 1984 STRASBOURG (accepted)

[25] LALLE P., CEA/CESTA private communication

[26] BARKER L.M. , HOLIENBACH R.E., J. App1.Phys 45 (1974)

27] YOUNG C. et a1., "Proceedings of the 17 th Sagamore Army Research Materials Conference" J.J. BURKE, V. WEISS Eds, Syracuse Un. Press (1971) 202

[28] HUANG ZHENGPING, ZHANG HANPING,"shock Waves in Condensed Matter" 1983 Elsevier Science Pub. BV (1984) 234

9] FOWLES R., WILIIAMS R.F., J. Appl. Phys. 41 (1970) 360

[30] COWPERTHWAITE M., WILLIAMS R.F., J. App1. Phys . 42 (1971) 456

[31] SEAMAN L., J.App1. Phys. 45 (1974) 4303

[32] ASAY J.R., LIPKIN J., J. App1. Phys. 49 (1978) 4242

[33] GUPTAY.M., J. App1. Phys. 51 (1980) 5352

[34] SWEGLE J.W., CHHABILDAS L. C., "Shock Wave and High Strain Rate Phenomena in Metals", M.A. MAYERS, L.E. MURR Eds Plenum Press (1981) 401

[35] BERNSTEIN D. et al., "Behaviour of Dense Media Under High Dynamic Pressures" GORDON and BREACH Pub. (1968)461

[36] CHARTAGNAC P.F., J. App1. Phys . 53 (1982) 948

[37] HERRMANN W. , J. Appl. Phys. 40 (1969) 2490

[38] MADER C.I., "12 th International Symposium on Combustion", WILLIAMS and WILKINS Co Pub. (1968) 701

[39] DAVISON L . et a1., J. Mech. Phys. Solids 25 (1977) 11

[40] DAVISON L., "Shock Waves in Condensed Matter"1983 Elsevier Science Pub. (1984) 181

[41] GIBSON F.C. et a1., J. App1. Phys. 29 (1958) 628

[42] KATO Y, et al, , Symposium HDP Paris CEA Ed (1978) 439

[43] VON HOLLE W., TRIMBLE J., "Proceedings of the 6 th International Symposium on Detonation" Office of Naval Research (1976) 691

[44] ROSENBERG Z., PARTOM Y., J. App1. Phys. 52 (1981)

[45] BOISARD F. et al., "Proceedings of the 7 th International Symposium on Detonation" (1981) 531 
[46] DELPUECH A., MENIL A., "Shock waves in [48] GRAHAM R.A., Sandia National LaboraCondensed Matter 1983", E1sevier tories Rept SAND 80-1642 (1980) Science Pub. BV (1984) 309

[49] DREMIN A.N, BREUSOV O.N., Priroda 12

47 ] GAUTHIER J.P., GUIX R. "Proceedings of the 15 th International Congress on High Speed Photography an Photonics", SPIE Pub. (1982) 747

[50] GRAHAM R.A., WEBB D.M., "Shock Waves in Condensed Matter 1983" E1sevier Science Pub. BV (1984) 211 